\title{
Patterns of metastasis and prognosis of elderly esophageal squamous cell carcinoma patients in stage IVB: a population-based study
}

\author{
Guanghao Qiu ${ }^{\#}$, Hanlu Zhang ${ }^{\#}$, Fuqiang Wang, Yu Zheng, Yun Wang^ \\ Department of Thoracic Surgery, West China Hospital, Sichuan University, Chengdu, China \\ Contributions: (I) Conception and design: G Qiu, H Zhang; (II) Administrative support: Y Wang; (III) Provision of study materials or patients: G Qiu, \\ H Zhang; (IV) Collection and assembly of data: F Wang, Y Zheng; (V) Data analysis and interpretation: All authors; (VI) Manuscript writing: All \\ authors; (VII) Final approval of manuscript: All authors. \\ "These authors contributed equally to this work. \\ Correspondence to: Yun Wang, MD, PhD. Department of Thoracic Surgery, West China Hospital, Sichuan University, No. 37, Guoxue Alley, Chengdu \\ 610041, China. Email: yunwwang@yeah.net.
}

Background: Esophageal squamous cell carcinoma (ESCC) has been listed among the most common esophageal cancers (ECs). Patients are generally relatively old in terms of their age at diagnosis of ESCC. A retrospective, population-based study appraising 537 elderly ESCC patients who suffered distant metastasis (DM) in stage IVB from 2010 to 2016 was performed. To this end, data pertaining to Surveillance, Epidemiology, and End Results (SEER) were adopted.

Methods: A total of 537 elderly patients with IVB-stage ESCC suffering DM treated from 2010 to 2016 were taken as subjects. Prognosis was determined by using Kaplan-Meier analysis, as well as univariate and multivariate Cox regression. In accordance with sites of metastasis, these patients were classified into five groups: bone-, lung-, brain-, liver-only, and multiple-site (metastases to two or more organs) groups. In order to assess the prognosis, the cancer-specific survival (CSS), median survival time (MST), overall survival (OS), and survival rate (SR) were examined.

Results: The lung was found to be the organ most vulnerable to metastasis in the population with singleorgan metastasis, and liver, bone and brain followed in descending rank order. Relative to the group only having bone metastasis, the multiple-site group had the lowest CSS (HR: 1.067; 95\% CI: 0.767-1.485; $\mathrm{P}=0.700$ ) and OS (HR: 1.051; 95\% CI: 0.759-1.454; P=0.766). The MST (MST: both 2 months in CSS and OS) and SR (6-month SR: 28.2\% in CSS, $27.7 \%$ in OS; 1-year SR: $7.5 \%$ in CSS, $6.7 \%$ in OS; 3-year SR: $2.5 \%$ in CSS, $1.5 \%$ in OS) were also found to be the lowest for the multiple-site group among the total population. These patients benefited from treatment with chemotherapy $(\mathrm{C})$, radiotherapy $(\mathrm{R})$, and surgery $(\mathrm{S})$, as evinced by the prognosis (CSS and OS: $\mathrm{P}<0.001$ ), in comparisons with untreated patients $(\mathrm{N})$ in the total population. The $\mathrm{S}$ or/and $\mathrm{R}+\mathrm{C}$ resulted in no statistically significant differences to $\mathrm{C}$ alone (CSS: $\mathrm{P}=0.593$; OS: $\mathrm{P}=0.510$ ) in terms of the prognostic results, which indicated that $\mathrm{C}$ alone can have almost the same prognostic effect as multimodal therapy.

Conclusions: Population-based research was used to determine patterns of metastasis and survival outcomes of elderly patients with IVB-stage ESCC suffering DM. The worst CSS and OS were found in patients with multiple-site metastasis across all groups. The treatment is an independent prognostic factor affecting prognosis. Chemotherapy plays a vital role in prognosis. Active therapies are beneficial to elderly patients with IVB-stage ESCC suffering DM, particularly chemotherapy.

^ ORCID: Guanghao Qiu, 0000-0002-9816-311x; Yun Wang, 0000-0002-9685-7337. 
Keywords: Esophageal squamous cell carcinoma (ESCC); elderly patients; prognosis; metastasis; treatment

Submitted Jun 30, 2021. Accepted for publication Oct 22, 2021.

doi: $10.21037 /$ tcr-21-1128

View this article at: https://dx.doi.org/10.21037/tcr-21-1128

\section{Introduction}

Esophageal cancers (ECs) rank the sixth among causes for global cancer-associated mortality and the seventh in the United States, with increasing incidence at time of writing $(1,2)$. Cell populations of esophageal squamous cell carcinoma (ESCC) are taken from squamous epithelium and the most common site of ESCC is the mid-thoracic esophagus (3).

As human life expectancy increases, more people will develop EC. As shown on the website of Cancer Research UK, most EC patients (exceeding 73\%) were over 65 years of age (4); however, aged EC patients suffering distant metastasis (DM) still remain poorly studied. The death of EC patients is the result of numerous causes, such as local large blood-vessel invasion, cachexia, nutritional disorders, etc. Whereas, clinical research has identified DM as the most probable cause of death (5). EC patients suffering DM generally had poor prognosis and more than half of these patients were found to have metastases to distant organ or lymph nodes upon first diagnosis. Considering this, deducing patterns of metastasis and prognosis in aged EC patients suffering DM is important $(5,6)$.

The Surveillance, Epidemiology, and End Results (SEER) database was used for probing DM patterns and prognosis of a large elderly ESCC cohort that is divided into several different metastasis group. Patients over 65 years of age were included as the elderly cohort. We present the following article in accordance with the STROBE reporting checklist (available at https://dx.doi.org/10.21037/tcr-211128).

\section{Methods}

\section{Data acquisition}

SEER 18-registry custom data of the NCI were studied, which included additional treatment fields [1975-2016] and a dataset that was submitted in November 2018. The following eligibility criteria were used: (I) aged 65 years, or older; (II) defining ESCC using the histology codes 80708094; (III) the upper, middle, and lower esophagi as well as others were separately defined by "cervical esophagus" (primary site codes C15.0) + "upper third of esophagus" (primary site codes C15.3), "middle third of esophagus" (primary site codes C15.4), "abdominal esophagus" (primary site codes C15.2) + "lower third of esophagus" (primary site codes C15.5) and "thoracic esophagus" (primary site codes C15.1) + "overlapping lesion of esophagus" (primary site codes C15.8) + "esophagus, NOS" (primary site codes C15.9); (4) patients in stage IVB (as only four relating site-specific DMs included in the SEER database). The following was used as exclusion criteria: patients without histological diagnosis, without survival data, and without follow-up data were excluded by selecting the values "histologically confirmed positive", "complete dates are available and there are 0 days of survival", "complete dates available and more than 0 days of survival" and "active follow-up". In these groups with single and multiorgan metastasis, both cancer-specific survival (CSS) and overall survival (OS) were investigated. Other clinical and pathological parameters were also adopted, including: gender, grade, race, locus of ESCC, N stage, T stage, and treatment(s). All data came from the SEER dataset and CSS, OS, median survival time (MST), and survival rate (SR) were analysed. Patients were classified into different groups, i.e., bone-, brain-, lung-, and liver-only groups as well as a multiple-site group according to sites of metastasis. Patients can be further grouped according to different treatments. Incomplete chemotherapy data can lead to bias. In accordance with the aforementioned eligibility criteria, a total of 537 elderly ESCC patients diagnosed with DM at stage IVB from 2010 to 2016 were selected as subjects (note that site-specific metastatic information was not recorded in the SEER database until 2010). The study was conducted in accordance with the Declaration of Helsinki (as revised in 2013). This study was approved by the Ethics Committee of West China Hospital (2021-385). Patient consent is not required because the data are sourced from the SEER database.

\section{Statistical analysis}

The two-sample $t$-test was conducted to analyse 
Table 1 Characteristics of elderly ESCC patients suffering DM

\begin{tabular}{|c|c|}
\hline Characteristics & $\geq 65, \mathrm{n}(\%)$ \\
\hline \multicolumn{2}{|l|}{ Sex } \\
\hline Male & 393 (73.2) \\
\hline Female & $144(26.8)$ \\
\hline \multicolumn{2}{|l|}{ Ethnicity } \\
\hline White & $351(65.4)$ \\
\hline Black & $119(22.2)$ \\
\hline Other & $67(12.4)$ \\
\hline \multicolumn{2}{|l|}{ Grade } \\
\hline I & $8(1.5)$ \\
\hline II & $161(30.0)$ \\
\hline III & 247 (46.0) \\
\hline IV & $6(1.1)$ \\
\hline Unknown & 115 (21.4) \\
\hline \multicolumn{2}{|l|}{ T stage } \\
\hline $\mathrm{T} 1$ & $128(23.8)$ \\
\hline $\mathrm{T} 2$ & $16(3.0)$ \\
\hline T3 & $68(12.7)$ \\
\hline $\mathrm{T} 4$ & $96(17.9)$ \\
\hline Unknown & 229 (42.6) \\
\hline \multicolumn{2}{|l|}{$\mathrm{N}$ stage } \\
\hline No & 127 (23.6) \\
\hline $\mathrm{N} 1$ & 213 (39.7) \\
\hline $\mathrm{N} 2$ & $42(7.8)$ \\
\hline N3 & $15(2.8)$ \\
\hline Unknown & $140(26.1)$ \\
\hline \multicolumn{2}{|l|}{ Site of ESCC } \\
\hline Upper & 77 (14.3) \\
\hline Middle & $147(27.4)$ \\
\hline Lower & 176 (32.8) \\
\hline Other & $137(25.5)$ \\
\hline \multicolumn{2}{|l|}{ Metastasis } \\
\hline Bone-only & $59(11.0)$ \\
\hline Brain-only & $8(1.5)$ \\
\hline Liver-only & $130(24.2)$ \\
\hline Lung-only & $191(35.6)$ \\
\hline Multiple & $149(27.7)$ \\
\hline
\end{tabular}

Table 1 (continued)
Table 1 (continued)

\begin{tabular}{lc}
\hline Characteristics & $\geq 65, \mathrm{n}(\%)$ \\
\hline Treatment & $153(28.5)$ \\
S or/and R + C & $109(20.3)$ \\
$\mathrm{C}$ & $91(16.9)$ \\
$\mathrm{S}$ or/and R & $184(34.3)$ \\
$\mathrm{N}$ & \\
\hline ESCC, esophageal squamous cell carcinoma; DM, distant \\
metastasis; S, surgery; R, radiotherapy; C, chemotherapy; N, no \\
treatment.
\end{tabular}

continuous variables. The results were deemed to be of statistical significance if two-tailed $\mathrm{P}$ values were below 0.05. Pearson's chi-squared test statistic was selected for categorical variables to compare demographic and clinical characteristics of patients across various groups. Differences among Kaplan-Meier survival curves attained in the logrank test were used. Prognostic effects of the CSS and OS were evaluated by conducting univariate and multivariate Cox regression analyses. Statistical analysis was realized by use of GraphPad Prism 8.0 and SPSS 25 software.

\section{Results}

\section{Demographics}

Table 1 lists baseline characteristics and demographic data pertaining to those 537 elderly ESCC patients, with 393 $(73.2 \%)$ male and $351(65.4 \%)$ Caucasian patients. The most common metastasis site was lung-only (35.6\%), followed by liver-only (24.2\%), bone-only (11.0\%), and brain-only $(1.5 \%)$. The group with multiple metastatic sites contained 149 (27.7\%) patients. Most tumors were located in the middle $179(33.3 \%)$ and lower esophagus $176(32.8 \%)$. One hundred and fifty-three (28.5\%) patients had surgery (S) or/and radiotherapy (R) + chemotherapy (C), followed by $\mathrm{C}$ alone (20.3\%) and S or/and R (16.9\%). Surprisingly, $184(34.3 \%)$ patients did not receive any treatment. The selection of patients from the SEER database is shown in a flow chart (Figure 1).

\section{Risk detection pertaining to metastasis to various organs and treatments}

The univariate and multivariate analysis results of 


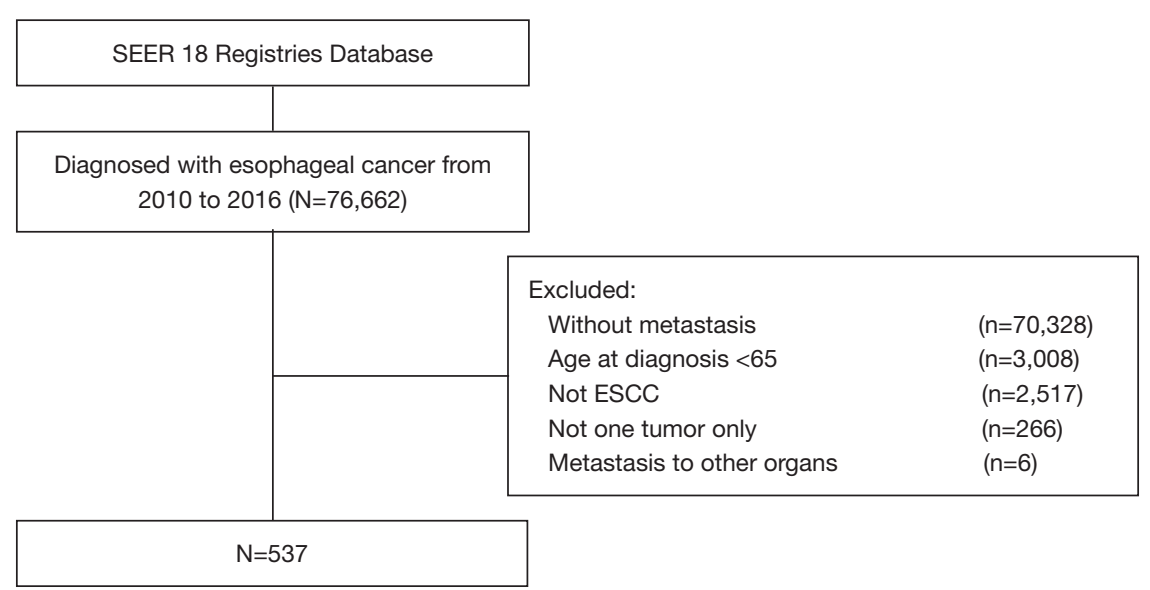

Figure 1 Selection flow chart of patients from the SEER database [2010-2016]. SEER, Surveillance, Epidemiology, and End Results; ESCC, esophageal squamous cell carcinoma.

ESCC patients with distinct DMs conclude that therapy influencing CSS and OS is the only independent prognostic factor (Tables 2,3).

It can be seen from Table 2 that different therapeutic methods varied in terms of their prognostic effects. In comparison with $\mathrm{S}$ or/and $\mathrm{R}+\mathrm{C}$ group, $\mathrm{OS}$ was worse in the $\mathrm{S}$ or/and R group (HR: 2.146; 95\% CI: 1.619-2.845; $\mathrm{P}<0.001)$ and worst in the untreated patients $(\mathrm{N})$ group (HR: 3.564; 95\% CI: 2.787-4.558; $\mathrm{P}<0.001$ ). OS results of $\mathrm{S}$ or/and $\mathrm{R}+\mathrm{C}$ group and $\mathrm{C}$ group were not statistically significant (HR: 0.917; 95\% CI: 0.695-1.212; $\mathrm{P}=0.544$ ). The OS was better in the lung-only group (HR: 0.628; 95\% CI: $0.455-0.867 ; \mathrm{P}<0.05)$ relative to the bone-only group. The bone-only and multiple-site groups exhibited no statistical significance regarding OS results (HR: 1.051; 95\% CI: $0.759-1.454 ; \mathrm{P}=0.766)$. CSS was found to have similar results. Table 2 displays that among groups suffering metastasis to single organs, OS and CSS are the worst in the bone-only group.

Data in Table 3 show that, since the brain-only group does not contain enough patients (only eight patients), it is impossible to attain results of statistical significance. For that reason, the brain-only group was not included in subsequent calculations. Similar results were attained in three groups (liver- and lung-only as well as multiplesite groups), which were similar to the results of total population and show that in comparison with the $\mathrm{S}$ or/and $\mathrm{R}+\mathrm{C}$ group, a poorer and the poorest OS and CSS were noticed in the $\mathrm{S}$ or/and $\mathrm{R}$ group and $\mathrm{N}$ group. Furthermore, no statistically significant conclusions could be drawn for the $\mathrm{C}$ group compared with $\mathrm{S}$ or/and $\mathrm{R}+\mathrm{C}$ group in $\mathrm{OS}$ and CSS.

In the bone-, brain-, lung-, and liver-only, as well as the multiple-site group and total population, the MSTs in CSS were $3,8,4,5,2$, and 4 months and in OS were $3,8,4,4$, 2 , and 3 months, respectively (Table 4). The lowest SR was found in the multiple-site group (6-month SR: $28.2 \%$ in CSS, $27.7 \%$ in OS; 1-year SR: $7.5 \%$ in CSS, $6.7 \%$ in OS; 3 -year SR: $2.5 \%$ in CSS, $1.5 \%$ in OS). According to these results, among the total population, patients subjected to metastases to multiple sites had the worst 6 -month and 1-year SRs; while those in the bone-only group exhibited the worst 6-month and 1-year SRs across the groups of single-organ metastasis.

To obtain the data plotted in Figure 2, a Kaplan-Meier survival analysis was undertaken among elderly patients in different groups to ascertain the relationship of these therapies with prognosis. In Figure 2A,2B, the prognosis of patients treated with different therapies varied greatly across the total population. Whether a patient was treated with $\mathrm{R}$ or $\mathrm{S}$, the patient receiving chemotherapy treatment always had a better prognosis than one without chemotherapy (compared with $\mathrm{S}$ or/and $\mathrm{R}$ and $\mathrm{N}$ : $\mathrm{P}<0.001)$. Nevertheless, $\mathrm{S}$ or/and $\mathrm{R}+\mathrm{C}$ showed no statistically significant difference with $\mathrm{C}$ alone in the prognosis (CSS: $\mathrm{P}=0.593$; $\mathrm{OS}$ : $\mathrm{P}=0.510$ ). The liver-only, lung-only, and multiple-site groups also had similar results (Figure 2E-2f). Figure 2C,2D show that the bone-only group did not have statistical significance in the prognostic results of different treatments, including $\mathrm{S}$ or/ and $\mathrm{R}+\mathrm{C}, \mathrm{C}$ alone, and $\mathrm{S}$ or/and $\mathrm{R}$. 
Table 2 Univariate and multivariate analysis results of the study population based on the COX proportional hazards model

\begin{tabular}{|c|c|c|c|c|c|c|c|c|}
\hline \multirow{2}{*}{ Variance } & \multicolumn{2}{|c|}{ Univariate analysis (OS) } & \multicolumn{2}{|c|}{ Multivariate analysis (OS) } & \multicolumn{2}{|c|}{ Univariate analysis (CSS) } & \multicolumn{2}{|c|}{ Multivariate analysis (CSS) } \\
\hline & $\mathrm{HR}(95 \% \mathrm{Cl})$ & $P$ value & $\mathrm{HR}(95 \% \mathrm{Cl})$ & $P$ value & $\mathrm{HR}(95 \% \mathrm{Cl})$ & $P$ value & $\mathrm{HR}(95 \% \mathrm{Cl})$ & $P$ value \\
\hline \multicolumn{9}{|l|}{ Sex } \\
\hline Female & $0.916(0.751-1.118)$ & 0.388 & $0.829(0.674-1.020)$ & 0.076 & $0.941(0.768-1.153)$ & 0.556 & $0.857(0.693-1.058)$ & 0.151 \\
\hline \multicolumn{9}{|l|}{ Ethnicity } \\
\hline White & - & - & & & - & - & & \\
\hline Other & $0.793(0.599-1.048)$ & 0.103 & $0.696(0.519-0.934)$ & 0.016 & $0.794(0.597-1.055)$ & 0.112 & $0.699(0.519-0.943)$ & 0.019 \\
\hline \multicolumn{9}{|l|}{ Grade } \\
\hline 1 & - & - & & & - & - & & \\
\hline II & $0.944(0.463-1.923)$ & 0.874 & $1.229(0.587-2.570)$ & 0.585 & $0.873(0.428-1.781)$ & 0.709 & $1.165(0.555-2.447)$ & 0.686 \\
\hline T1 & - & - & & & - & - & & \\
\hline $\mathrm{T} 2$ & $0.756(0.447-1.276)$ & 0.295 & $0.606(0.349-1.052)$ & 0.075 & $0.732(0.427-1.257)$ & 0.258 & $0.591(0.334-1.043)$ & 0.069 \\
\hline T3 & $0.733(0.535-1.005)$ & 0.054 & $0.869(0.623-1.212)$ & 0.408 & $0.740(0.538-1.017)$ & 0.064 & $0.890(0.636-1.246)$ & 0.498 \\
\hline $\mathrm{T} 4$ & $1.204(0.915-1.583)$ & 0.184 & $1.203(0.908-1.595)$ & 0.199 & $1.164(0.880-1.540)$ & 0.287 & $1.181(0.885-1.575)$ & 0.259 \\
\hline Unknown & $1.005(0.803-1.259)$ & 0.965 & $1.025(0.810-1.298)$ & 0.836 & $0.969(0.771-1.220)$ & 0.791 & $0.996(0.783-1.267)$ & 0.973 \\
\hline \multicolumn{9}{|l|}{$\mathrm{N}$ stage } \\
\hline No & - & - & & & - & - & & \\
\hline N1 & $0.855(0.682-1.071)$ & 0.173 & $0.946(0.746-1.199)$ & 0.646 & $0.815(0.648-1.024)$ & 0.080 & $0.900(0.708-1.144)$ & 0.390 \\
\hline N2 & $0.965(0.679-1.373)$ & 0.845 & $1.096(0.754-1.595)$ & 0.630 & $0.899(0.626-1.291)$ & 0.563 & $1.004(0.682-1.477)$ & 0.985 \\
\hline Other & $1.015(0.758-1.359)$ & 0.919 & $0.999(0.731-1.365)$ & 0.995 & $1.023(0.758-1.381)$ & 0.881 & $0.977(0.710-1.346)$ & 0.888 \\
\hline \multicolumn{9}{|l|}{$\begin{array}{l}\text { Site of } \\
\text { metastasis }\end{array}$} \\
\hline Bone-only & - & - & & & - & - & & \\
\hline Brain-only & $0.609(0.290-1.281)$ & 0.192 & $0.599(0.279-1.290)$ & 0.191 & $0.633(0.300-1.333)$ & 0.229 & $0.628(0.291-1.354)$ & 0.235 \\
\hline Liver-only & $0.863(0.626-1.190)$ & 0.369 & $0.858(0.610-1.207)$ & 0.379 & $0.876(0.632-1.214)$ & 0.427 & $0.879(0.621-1.245)$ & 0.468 \\
\hline Lung-only & $0.768(0.566-1.043)$ & 0.091 & $0.628(0.455-0.867)$ & 0.005 & $0.738(0.539-1.009)$ & 0.057 & $0.608(0.437-0.845)$ & 0.003 \\
\hline Multiple & $1.085(0.793-1.483)$ & 0.611 & $1.051(0.759-1.454)$ & 0.766 & $1.096(0.797-1.506)$ & 0.574 & $1.067(0.767-1.485)$ & 0.700 \\
\hline \multicolumn{9}{|l|}{ Treatment } \\
\hline $\begin{array}{l}\text { S or/and R+ } \\
\mathrm{C}\end{array}$ & - & - & & & - & - & & \\
\hline $\mathrm{C}$ & $1.073(0.825-1.396)$ & 0.598 & $0.917(0.695-1.212)$ & 0.544 & $1.056(0.808-1.381)$ & 0.688 & $0.898(0.676-1.192)$ & 0.456 \\
\hline $\mathrm{S}$ or/and $\mathrm{R}$ & $2.032(1.545-2.672)$ & 0.000 & $2.146(1.619-2.845)$ & 0.000 & $2.012(1.523-2.658)$ & 0.000 & $2.136(1.604-2.845)$ & 0.000 \\
\hline $\mathrm{N}$ & $3.480(2.751-4.401)$ & 0.000 & $3.564(2.787-4.558)$ & 0.000 & $3.347(2.631-4.257)$ & 0.000 & $3.453(2.684-4.444)$ & 0.000 \\
\hline
\end{tabular}

OS, overall survival; CSS, cancer-specific survival; ESCC, esophageal squamous cell carcinoma; S, surgery; R, radiotherapy; C, chemotherapy; N, no treatment. 
Table 3 Multivariate analysis results of different populations based on the COX proportional hazards model

\begin{tabular}{|c|c|c|c|c|c|}
\hline Site of metastasis, $\mathrm{n}(\%)$ & Treatment & \multicolumn{2}{|l|}{ OS } & \multicolumn{2}{|l|}{ CSS } \\
\hline \multirow[t]{3}{*}{ Bone, 59 (11.0) } & $\mathrm{S}$ or/and $\mathrm{R}+\mathrm{C}$ & - & - & - & - \\
\hline & C & $3.326(1.168-9.468)$ & 0.024 & $3.139(1.100-8.961)$ & 0.033 \\
\hline & S or/and R & $2.413(0.929-6.268)$ & 0.070 & 2.405 (0.912-6.339) & 0.076 \\
\hline \multirow[t]{4}{*}{ Liver, 130 (24.2) } & $\mathrm{S}$ or/and $\mathrm{R}+\mathrm{C}$ & - & - & - & - \\
\hline & $\mathrm{C}$ & $1.380(0.757-2.514)$ & 0.293 & $1.380(0.749-2.545)$ & 0.302 \\
\hline & S or/and R & 3.478 (1.581-7.649) & 0.002 & 3.533 (1.598-7.810) & 0.002 \\
\hline & $\mathrm{N}$ & 9.196 (4.649-18.190) & 0.000 & $9.218(4.612-18.425)$ & 0.000 \\
\hline \multirow{2}{*}{ Lung, 191 (35.6) } & S or/and R & $1.979(1.398-3.631)$ & 0.001 & $2.262(1.384-3.696)$ & 0.001 \\
\hline & $\mathrm{N}$ & $3.393(2.221-5.185)$ & 0.000 & $3.238(2.078-5.044)$ & 0.000 \\
\hline \multirow[t]{4}{*}{ Multiple, 149 (27.7) } & $\mathrm{S}$ or/and $\mathrm{R}+\mathrm{C}$ & - & - & - & - \\
\hline & $\mathrm{C}$ & $1.092(0.611-1.952)$ & 0.766 & $1.109(0.617-1.995)$ & 0.729 \\
\hline & $\mathrm{S}$ or/and $\mathrm{R}$ & $3.391(1.856-6.197)$ & 0.000 & $3.490(1.902-6.404)$ & 0.000 \\
\hline & $\mathrm{N}$ & $4.702(2.662-8.305)$ & 0.000 & 4.649 (2.609-8.286) & 0.000 \\
\hline
\end{tabular}

OS, overall survival; CSS, cancer-specific survival; S, surgery; R, radiotherapy; C, chemotherapy; N, no treatment.

\section{Discussion}

EC is among the most common malignant tumors worldwide and usually has poor prognosis. Due to poor prognosis and high metastasis frequency in EC patients, this study revealed the metastasis pattern of elderly ESCC patients with DM and the prognostic results under different treatment modalities. Despite significant advances in chemotherapy, surgical techniques, and radiotherapy, the 5 -year SR for EC remained only 20-30\% (7).

This study demonstrated that the lung $(35.6 \%)$ is the most common metastatic site for ESCC, which is different from esophageal adenocarcinoma (with liver as the most common metastatic site) (8). A study of 35 patients from China with ESCC and DM revealed that $22(62.9 \%)$ patients had lung metastasis (9). Several studies from Japan report that the most common metastatic site of ESCC is the lung (10-12).

At diagnosis, EC is generally shown as transmural invasion, accompanied by early and advanced metastasis spread. According to the 8th TNM classification by UICC and AJCC, EC patients with DM are regarded as being at stage IVB. These patients are often taken as candidates for palliative treatments, such as stent placement, photodynamic therapy, palliative chemotherapy or radiotherapy, and so on (13-17), thus, they generally have poor prognosis.

The current study demonstrates that ESCC elderly patients with DM showed different prognostic results due to the different DM sites and multimodality treatment could improve OS and CSS in the study population.

There are seldom existing studies on effects of DM sites on survival of metastatic EC patients; however, Chen et al. identified multimodality of treatment and the quantity of metastatic lesions to be independent prognostic factors in ESCC with DM. In addition, multimodal treatment can improve patient survival, but C alone cannot be a favorable prognostic factor (18). Although the number of Phase III clinical trials of EC demonstrating the positive effect of chemotherapy is limited, systemic chemotherapy is widely applied as the standard treatment of patients with DM, in comparison with radiotherapy, a locally treatment modality (19). The above results prove that the $\mathrm{S}$ or/and $\mathrm{R}+\mathrm{C}$ does not 
Table 4 Analysis of prognosis across different populations

\begin{tabular}{|c|c|c|}
\hline Site of metastasis & os & CSS \\
\hline \multicolumn{3}{|l|}{ Bone } \\
\hline MST (month) & 3 & 3 \\
\hline 6-month SR (\%) & 26.9 & 28.3 \\
\hline 1-year SR (\%) & 8.4 & 8.9 \\
\hline \multicolumn{3}{|l|}{ Brain } \\
\hline MST (month) & 8 & 8 \\
\hline 6-month SR (\%) & 62.5 & 62.5 \\
\hline 1-year SR (\%) & 25.0 & 25.0 \\
\hline MST (month) & 4 & 4 \\
\hline 6-month SR (\%) & 29.0 & 29.6 \\
\hline 1-year SR (\%) & 16.5 & 16.8 \\
\hline 3-year SR (\%) & 1.2 & 1.4 \\
\hline \multicolumn{3}{|l|}{ Lung } \\
\hline MST (month) & 4 & 5 \\
\hline 6-month SR (\%) & 35.7 & 38.5 \\
\hline 1-year SR (\%) & 13.0 & 15.9 \\
\hline \multicolumn{3}{|l|}{ Multiple } \\
\hline 3-year SR (\%) & 1.5 & 2.5 \\
\hline \multicolumn{3}{|l|}{ Total } \\
\hline MST (month) & 3 & 4 \\
\hline 6-month SR (\%) & 31.3 & 3.8 \\
\hline 1-year SR (\%) & 11.8 & 13.2 \\
\hline 3-year SR (\%) & 3.1 & 3.9 \\
\hline
\end{tabular}

OS, overall survival; CSS, cancer-specific survival; MST, median survival time; SR, survival rate.

have statistical significance in prognostic results compared with $\mathrm{C}$ alone, which means that chemotherapy has a crucial function in treating ESCC patients suffering DM.

Radiotherapy, surgery, and chemotherapy, in some sense, may actually be deemed therapies for palliative care of EC patients suffering DM, whereas, the research findings show that $\mathrm{N}, \mathrm{S}$ or/and $\mathrm{R}$, and $\mathrm{S}$ or/and $\mathrm{R}+\mathrm{C}$ or $\mathrm{C}$ alone are listed (in ascending rank order) by their prognosis (Figure 2). Furthermore, chemotherapy is obviously beneficial to prognosis. Results also showed that no matter whether 
A

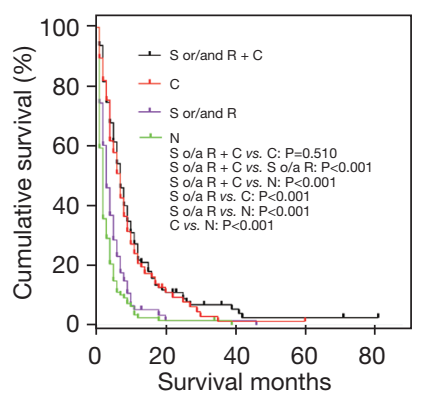

E
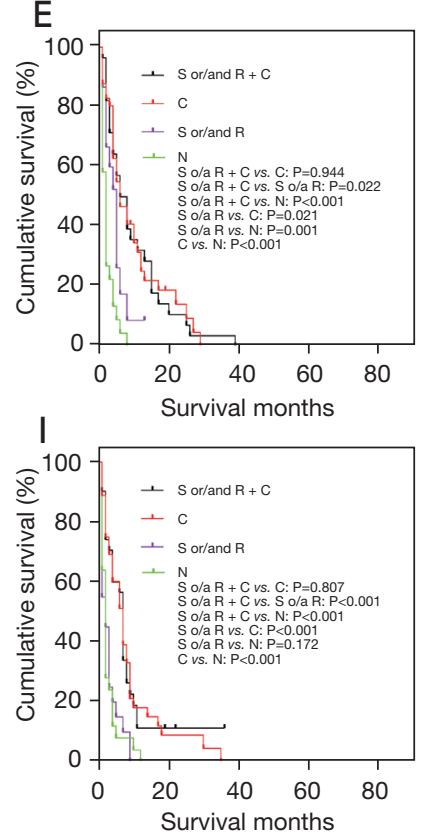

B

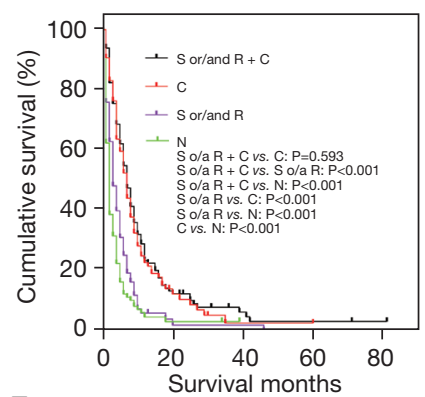

$\mathrm{F}$
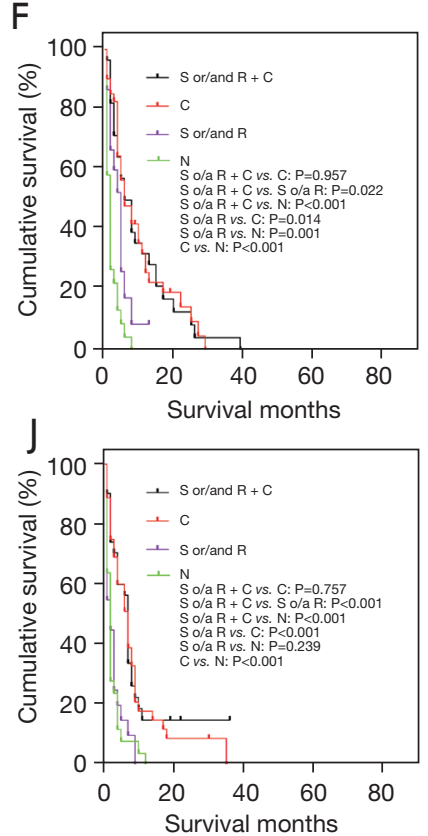

C

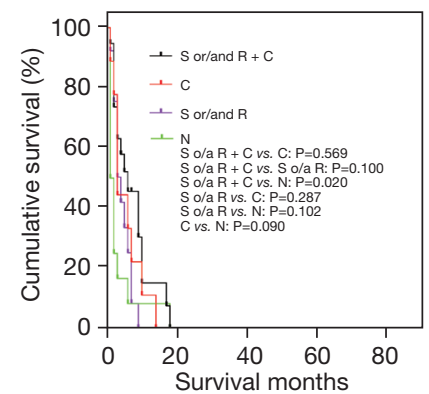

G
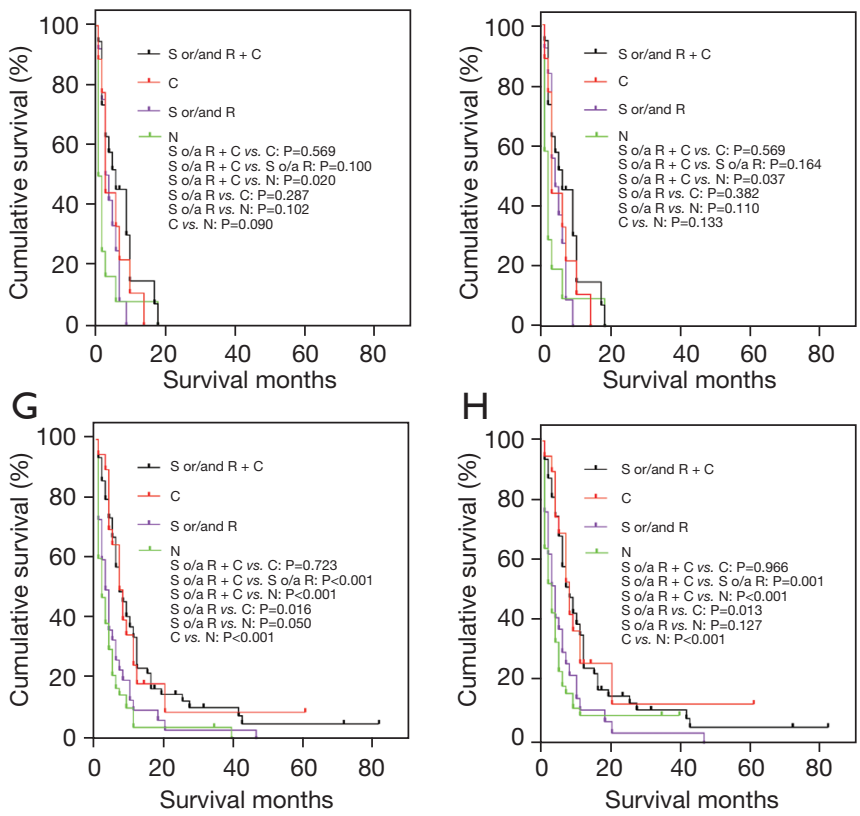

$\mathrm{H}$

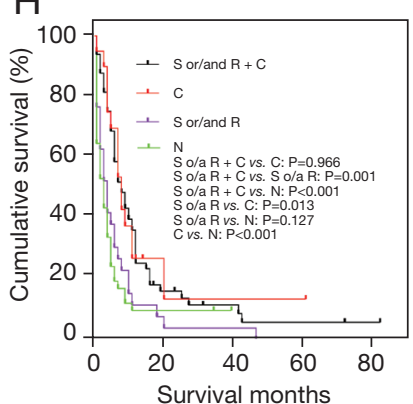

Figure 2 Kaplan-Meier curves of OS (A) and CSS (B) attained using various therapies in the whole population; OS (C) and CSS (D) in bone-only group; OS (E) and CSS (F) in liver-only group; OS (G) and CSS (H) in lung-only group; and OS (I) and CSS (J) in multiple-site group. OS, overall survival; CSS, cancer-specific survival; S, surgery; R, radiotherapy; C, chemotherapy; N, no treatment.

radiotherapy or surgery was performed for elderly patients or not, chemotherapy greatly affected prognosis. Because only three patients received surgery, the results mainly described effects of chemotherapy and radiotherapy upon prognosis of the patients. Results indicated that prognosis of patients is significantly improved by active treatments, and chemotherapy plays an important part in prognosis. It is concluded that surgery (even if only palliative surgery), radiotherapy (e.g., stereotactic radiotherapy and radiofrequency ablation) and chemotherapy (indispensable for patients with DM) are beneficial to prolonging survival time. No statistical significance is found in the results of the bone-only group in terms of difference across various treatment modalities. The reason for that is probably due to the lack of patients. Using only 59 patients cannot allow statistically significant results to be deduced. If a group had enough patients, we can conclude similar results as in the other groups.

It is suggested that multimodal therapy is essential for locally advanced primary EC patients, however, efficacy of multimodal therapy for DM patients in stage IVB has not been clarified. In our study, for the patients treated with chemotherapy, radiotherapy and surgery cannot be considered beneficial for the prognosis: chemotherapy can be regarded as the primary therapy.

This study has some limitations. The SEER database lacks details on chemotherapy (only two options: yes and no/unknown) and other sites of DM (only four organs), 
which affects the results of prognostic analysis and the selection of patients. This database is based on the American population and therefore lacks representativeness of the global population. The research failed to differentiate further between patterns of multiple metastatic sites, such as metastases to bone and lung, to liver and lung, to bone and liver, and to bone, liver, and lung. Other treatment modalities such as immunotherapy and targeted therapy cannot be considered. As drawbacks are present in the database, it is impossible to obtain detailed information about therapies including surgery, chemotherapy, and radiotherapy, whereas, there is a lack of relevant reports on elderly ESCC patients suffering DM in stage IVB, so the research is very significant.

To sum up, the research investigated survival outcomes and metastasis patterns of elderly ESCC patients suffering DM in stage IVB. The prognosis of patients showing different metastatic sites is not statistically different. The patients with chemotherapy only and S or/and $\mathrm{R}+\mathrm{C}$ did not exhibit statistical differences in terms of prognosis. Chemotherapy was necessary for elderly ESCC patients with DM: however, anti-cancer treatments were not performed in more than $34 \%$ of cases involving patients over 65 years of age. In the total study population, cancerspecific death was found to have the highest rate among these patients.

\section{Acknowledgments}

Funding: This study was supported by grants from the National Key Research Project of China (No. 2017YFC0113502) and Key Research Project of Sichuan Province (No. 2020YFS0249).

\section{Footnote}

Reporting Checklist: The authors have completed the STROBE reporting checklist. Available at https://dx.doi. org/10.21037/tcr-21-1128

Peer Review File: Available at https://dx.doi.org/10.21037/ tcr-21-1128

Conflicts of Interest: All authors have completed the ICMJE uniform disclosure form (available at https://dx.doi. org/10.21037/tcr-21-1128). All authors report this study was supported by grants from the National Key Research Project of China (No. 2017YFC0113502) and Key Research
Project of Sichuan Province (No. 2020YFS0249). The authors have no other conflicts of interest to declare.

Ethical Statement: The authors are accountable for all aspects of the work in ensuring that questions related to the accuracy or integrity of any part of the work are appropriately investigated and resolved. The study was conducted in accordance with the Declaration of Helsinki (as revised in 2013). This study was approved by the Ethics Committee of West China Hospital (2021-385). Patient consent is not required because the data are sourced from the SEER database.

Open Access Statement: This is an Open Access article distributed in accordance with the Creative Commons Attribution-NonCommercial-NoDerivs 4.0 International License (CC BY-NC-ND 4.0), which permits the noncommercial replication and distribution of the article with the strict proviso that no changes or edits are made and the original work is properly cited (including links to both the formal publication through the relevant DOI and the license). See: https://creativecommons.org/licenses/by-nc-nd/4.0/.

\section{References}

1. Torre LA, Bray F, Siegel RL, et al. Global cancer statistics, 2012. CA Cancer J Clin 2015;65:87-108.

2. Thrift AP, Whiteman DC. The incidence of esophageal adenocarcinoma continues to rise: analysis of period and birth cohort effects on recent trends. Ann Oncol 2012;23:3155-62.

3. Chang JT, Katzka DA. Gastroesophageal reflux disease, Barrett esophagus, and esophageal adenocarcinoma. Arch Intern Med 2004;164:1482-8.

4. Cancer Research UK. Oesophageal cancer incidence by age. Available online: https://www.cancerresearchuk.org/ health-professional/cancer-statistics/statistics-by-cancertype/oesophageal-cancer/incidence\#heading-One

5. Enzinger PC, Mayer RJ. Esophageal cancer. N Engl J Med 2003;349:2241-52.

6. Horner MJ, Ries LAG, Krapcho M, et al. SEER Cancer Statistics Review, 1975-2006. Available online: http://seer. cancer.gov/csr/1975_2006/ [Accessed May 10, 2017].

7. Liu JF, Wang QZ, Hou J. Surgical treatment for cancer of the oesophagus and gastric cardia in Hebei, China. Br J Surg 2004;91:90-8.

8. Ai D, Zhu H, Ren W, et al. Patterns of distant organ metastases in esophageal cancer: a population-based study. 
J Thorac Dis 2017;9:3023-30.

9. Wang Y, Wang L, Yang Q, et al. Patterns of recurrence in patients with stage pT3N0M0 thoracic esophageal squamous cell carcinoma after two-field esophagectomy. Zhonghua Zhong Liu Za Zhi 2016;38:48-54.

10. Ninomiya I, Okamoto K, Tsukada T, et al. Recurrence patterns and risk factors following thoracoscopic esophagectomy with radical lymph node dissection for thoracic esophageal squamous cell carcinoma. Mol Clin Oncol 2016;4:278-84.

11. Sugiyama M, Morita M, Yoshida R, et al. Patterns and time of recurrence after complete resection of esophageal cancer. Surg Today 2012;42:752-8.

12. Natsugoe S, Okumura H, Matsumoto M, et al. The role of salvage surgery for recurrence of esophageal squamous cell cancer. Eur J Surg Oncol 2006;32:544-7.

13. Mariette C, Piessen G, Triboulet JP. Therapeutic strategies in oesophageal carcinoma: role of surgery and other modalities. Lancet Oncol 2007;8:545-53.

Cite this article as: Qiu G, Zhang H, Wang F, Zheng Y, Wang Y. Patterns of metastasis and prognosis of elderly esophageal squamous cell carcinoma patients in stage IVB: a populationbased study. Transl Cancer Res 2021;10(11):4591-4600. doi: $10.21037 /$ tcr-21-1128
14. Homs MY, Kuipers EJ, Siersema PD. Palliative therapy. J Surg Oncol 2005;92:246-56.

15. Lightdale CJ. Esophageal cancer. American College of Gastroenterology. Am J Gastroenterol 1999;94:20-9.

16. Homs MY, Steyerberg EW, Eijkenboom WM, et al. Single-dose brachytherapy versus metal stent placement for the palliation of dysphagia from oesophageal cancer: multicentre randomised trial. Lancet 2004;364:1497-504.

17. Luketich JD, Christie NA, Buenaventura PO, et al. Endoscopic photodynamic therapy for obstructing esophageal cancer: 77 cases over a 2-year period. Surg Endosc 2000;14:653-7.

18. Chen MQ, Xu BH, Zhang YY. Analysis of prognostic factors for esophageal squamous cell carcinoma with distant organ metastasis at initial diagnosis. J Chin Med Assoc 2014;77:562-6.

19. Stahl M, Budach W, Meyer HJ, et al. Esophageal cancer: Clinical Practice Guidelines for diagnosis, treatment and follow-up. Ann Oncol 2010;21 Suppl 5:v46-9. 